\title{
Can a Combination of Poly(ethylene glycol) and Dense Phase Carbon Dioxide Improve Processing of Polylactide? A High Pressure Rheology Investigation.
}

Katie Jayne Pepper, Timothé Masson, Davide De Focatiis, Steven M Howdle.

\begin{abstract}
High temperature melts or use of organic solvents are not practicable approaches for encapsulating protein based or thermally labile drugs into degradable polymers. Here, we demonstrate that poly(ethylene glycol) (PEG) in combination with supercritical carbon dioxide $\left(\mathrm{scCO}_{2}\right)$ can dramatically reduce the viscosity of polymer melts allowing enhanced uptake of $\mathrm{CO}_{2}$ into poly(D,L-lactide) (PLA). Both PEG and $\mathrm{CO}_{2}$ are approved excipients in drug delivery and it is well documented that individually both are effective plasticisers. Using high pressure rheology techniques $\left(\mathrm{scCO}_{2}\right.$ at $\left.14 \mathrm{MPa}\right)$ we demonstrate a synergistic impact leading to significantly lower processing temperatures with PEG employed as both a blended additive and as a component of a block copolymer.
\end{abstract}

\section{Introduction}

Poly(D,L-lactide) (PLA) is an amorphous biodegradable, biocompatible polymer widely investigated for use in controlled release drug delivery systems.[1-3] Conventional processing of polymers via extrusion or injection moulding requires high temperatures and pressures in order to sufficiently reduce the melt viscosity. These are high energy operations which are not suitable for processing thermally sensitive active pharmaceutical ingredients (APIs) for drug delivery applications where polymers are employed to promote sustained release.[4] This is particularly true for APIs that are protein or peptide based. Poly(ethylene glycol) (PEG) is well-known to significantly plasticise PLA by reducing its glass transition temperature $\left(T_{g}\right)$ and has also been extensively studied as a processing aid.[5-11] Although reports clearly show reductions in viscosity and therefore improved processing, there is still a requirement for high temperatures to achieve low enough viscosities to allow efficient encapsulation, and these temperatures are still not suitable when processing proteins or peptides. Supercritical 
carbon dioxide $\left(\mathrm{SCCO}_{2}\right)$ has also been investigated as a promising alternative approach for low temperature processing of polymers. [12-20] In this paper we focus upon the combination of PEG and $\mathrm{scCO}_{2}$ and demonstrate a significant lowering of viscosity and process temperature for blends of PEG and PLA and also for new block copolymers (PEG- $b$-PLA) which are beginning to be used significantly in drug delivery. We exploit a high pressure rheometer to investigate quantitatively the combined effects of $\mathrm{scCO}_{2}$ and PEG.

Standard rheology has been used extensively to investigate various characteristics of polymer blends such as phase transitions and morphologies of immiscible polymers.[21] Other studies have explored viscoelasticity and interactions of blended polymers, [22] while earlier work by Xie et. al. used a capillary rheometer to identify changes in the viscosity of ultra-high molecular weight polyethylene (UHMWPE) when blended with PEG.[23] A large body of work has focused in the last decade on the melt rheology of polymer blends as this information is vital for the optimization of polymer processing.[8,22-28] In order to assess the efficiency of $\mathrm{scCO}_{2}$ as a processing aid, several high pressure rheology techniques have been developed.[29-38] Some of the first investigations into the effect of $\mathrm{CO}_{2}$ on polymer viscosity were performed by Gourgouillon using a high precision vibrating wire technique.[30] Most recently, Curia employed a high pressure rotational rheometer to explore the effect of $\mathrm{CO}_{2}$ on a semi-crystalline polymer, polycaprolactone (PCL).[38] In all cases it has been shown that $\mathrm{CO}_{2}$ can effectively reduce the viscosity of many different polymers ranging from polyethylene,[39] polypropylene[40] and polystyrene (PS)[31] through to PEG,[30] PCL[36,38] and PLA.[35] However, in most cases only the binary polymer $/ \mathrm{CO}_{2}$ system is studied. Very little has been reported on ternary systems, with $\mathrm{CO}_{2}$ PS/limonene[41] being one of the few systems studied and suspensions of fumed silica poly(propylene glycol) under high pressure $\mathrm{CO}_{2}$ being another.[42]

We now report on studies to quantify the combined effects of PEG and high pressure $\mathrm{CO}_{2}$ on the viscosity of amorphous PLA, building upon earlier studies by Kelly et. al. [43] which focused on the correlation between polymer miscibility and viscosity during blending, and demonstrated that high miscibility can be achieved with blend compositions between 8 and 25 wt\% PEG. In this paper, we probe for the first time the effect of PEG on the polymer melt viscosity in the presence of $\mathrm{CO}_{2}$ during blending and we carefully compare this to the effect of using comparable block copolymer structures. 


\section{Materials}

Amorphous poly(D,L-lactide) (PLA) $\left(M_{n} \sim 10.6 \mathrm{kDa}\right.$ by GPC) with $T_{g} \sim 49.90 \pm 0.04{ }^{\circ} \mathrm{C}$ measured by DSC was purchased from Evonik (Product code R202H) and used as received for the PEG/PLA blends. Poly(ethylene glycol) with a nominal molecular weight of $10 \mathrm{kDa}$ and $T_{m}$ $60.77 \pm 0.15{ }^{\circ} \mathrm{C}$ measured by DSC was purchased from Sigma Aldrich and used as received. Poly(ethylene glycol) methyl ether (PEG) $\left(M_{n} \sim 5.1 \mathrm{kDa}\right.$ by GPC) with $T_{m} \sim 59.13 \pm 0.08{ }^{\circ} \mathrm{C}$ by DSC was purchased from Sigma Aldrich and used as received for the PEG/PLA blends and as a macroinitiator for PEG- $b$-PLA copolymers after drying (see supporting information (SI) for synthesis details). For the synthesis of $5 \mathrm{kDa}$ PLA, D,L-lactide was purchased from Acros Organics and stored at $2-8{ }^{\circ} \mathrm{C}$ while benzyl alcohol and tin (II) 2-ethylhexanoate were purchased from Sigma Aldrich and stored at room temperature (see SI for details). HPLC grade THF used for GPC and ethanol were purchased from Fisher Scientific while deuterated chloroform for NMR was purchased from Sigma Aldrich. Food grade $\mathrm{CO}_{2}$ (99.8 \%) was purchased from BOC, UK for use in high pressure rheology experiments, while SFC grade $\mathrm{CO}_{2}$ (99.99\%) also from BOC, UK was used for the synthesis.

\section{Methods}

\section{Rheology}

Rheology was performed using an Anton Paar MCR 102 rheometer equipped with a high pressure electrically heated measuring cell (PP20/PR-STD parallel plate geometry with $20 \mathrm{~mm}$ diameter) and a Teledyne Isco 260D syringe pump.

Blend samples were produced by weighing the desired amount into a vial and simply shaking to mix the two powders, see Table 1 for composition details. 
Table 1 Weight \% composition for blends containing 5 kDa PEG, 10 kDa PEG and 5 kDa PLA with 10 kDa PLA. Subscript number is the number average molecular weight $(\mathrm{kDa})$ of the preceding polymer.

\begin{tabular}{|c|c|c|}
\hline Sample Name & \% Composition 5 kDa PEG & \% Composition 10 kDa PLA \\
\hline $\mathrm{PLA}_{10100}$ & 0 & 100 \\
\hline $\mathrm{PEG}_{5} 5: \mathrm{PLA}_{10} 95$ & 5 & 95 \\
\hline $\mathrm{PEG}_{5} 10: \mathrm{PLA}_{10} 90$ & 10 & 90 \\
\hline $\mathrm{PEG}_{5} 33: \mathrm{PLA}_{1067}$ & 33 & 67 \\
\hline $\mathrm{PEG}_{5} 50: \mathrm{PLA}_{10} 50$ & 50 & 50 \\
\hline $\mathrm{PEG}_{5} 100$ & 100 & 0 \\
\hline Sample Name & \% Composition 10 kDa PEG & \% Composition 10 kDa PLA \\
\hline $\mathrm{PEG}_{10} 100$ & 100 & 0 \\
\hline $\mathrm{PEG}_{1050: \mathrm{PLA}_{10} 50}$ & 50 & 50 \\
\hline Sample Name & \% Composition 5 kDa PLA & \% Composition 10 kDa PLA \\
\hline PLA 100 & 100 & 0 \\
\hline $\mathrm{PLA}_{5} 10: \mathrm{PLA}_{10} 90$ & 10 & 90 \\
\hline
\end{tabular}

Samples were loaded into the rheometer measuring cup and allowed to equilibrate at $80{ }^{\circ} \mathrm{C}$ for 1 hour. The quantity of polymer per measurement was determined by the melt volume, in order to ensure sufficient contact with the parallel plates. Consecutive shear ramps increasing logarithmically in shear rate from $0.1 \mathrm{~s}^{-1}$ to $1000 \mathrm{~s}^{-1}$ with a measuring point duration from 120 to 10 seconds across 30 measurement points were performed on each specimen with a 1 minute pause at $0.1 \mathrm{~s}^{-1}$ between each run. The samples were then pressurised to 140 bar with $\mathrm{CO}_{2}$ using the syringe pump and a 1 hour soak at constant shear rate of $10 \mathrm{~s}^{-1}$ started immediately. Following this, a series of shear ramps (as described above) were carried out every hour with a soak at constant shear rate of $10 \mathrm{~s}^{-1}$ between each one, (each measurement lasted 23 minutes followed by a 37 minute soak). Measurements were performed every hour for 6 hours after which further measurements were made at 9, 12, 15 and 18 hour time points. Average saturation viscosity was calculated as the average of the results from the point where saturation was achieved through to 18 hours (Figure S1). The time to saturation varied with the blend composition (Table S4). After completion of the high pressure studies, the rheometer was vented over 20 minutes with a constant shear rate of $100 \mathrm{~s}^{-1}$ and left to equilibrate for 10 minutes. Samples were then re-measured at ambient pressure, following the same procedure as the initial ambient pressure measurements. These conditions were employed because $80{ }^{\circ} \mathrm{C}$ was found to be the lowest temperature at which an ambient pressure viscosity measurement could be performed; while the pressure used was sufficient to ensure a significant viscosity decrease.[38] 
A Carreau model,[44] given by equation 1, was fitted to the viscosity - shear rate data using the Rheoplus software (Figure 1). The zero shear viscosity $\left(\eta_{0}(\mathrm{~Pa} . \mathrm{s})\right)$, is the sample viscosity at sufficiently low shear rates that the viscosity is independent of shear rate, while $\eta(\gamma)$ is the viscosity at the specific shear rate $\left(\dot{\gamma}\left(\mathrm{s}^{-1}\right)\right)$. Analysis was performed on all measurements, and the Carreau constants were determined from averaging the individual model fits from repeats of the same experiment. Parameter values are quoted as \pm 1 standard deviation from the mean. The relaxation time $(\lambda)$ is also obtained from the model fits, and provides information about the chain mobility and how this is influenced by the presence of $\mathrm{CO}_{2}$ or PEG. The Carreau exponent $(c)$ is related to the power law region and is obtained from the gradient of the shear thinning region. $[35,38]$

$$
\eta(\dot{\gamma})=\eta_{0}\left[1+(\dot{\gamma} \lambda)^{2}\right]^{-c}
$$

Three individual samples were analysed for each blend composition and for each of the neat polymers.

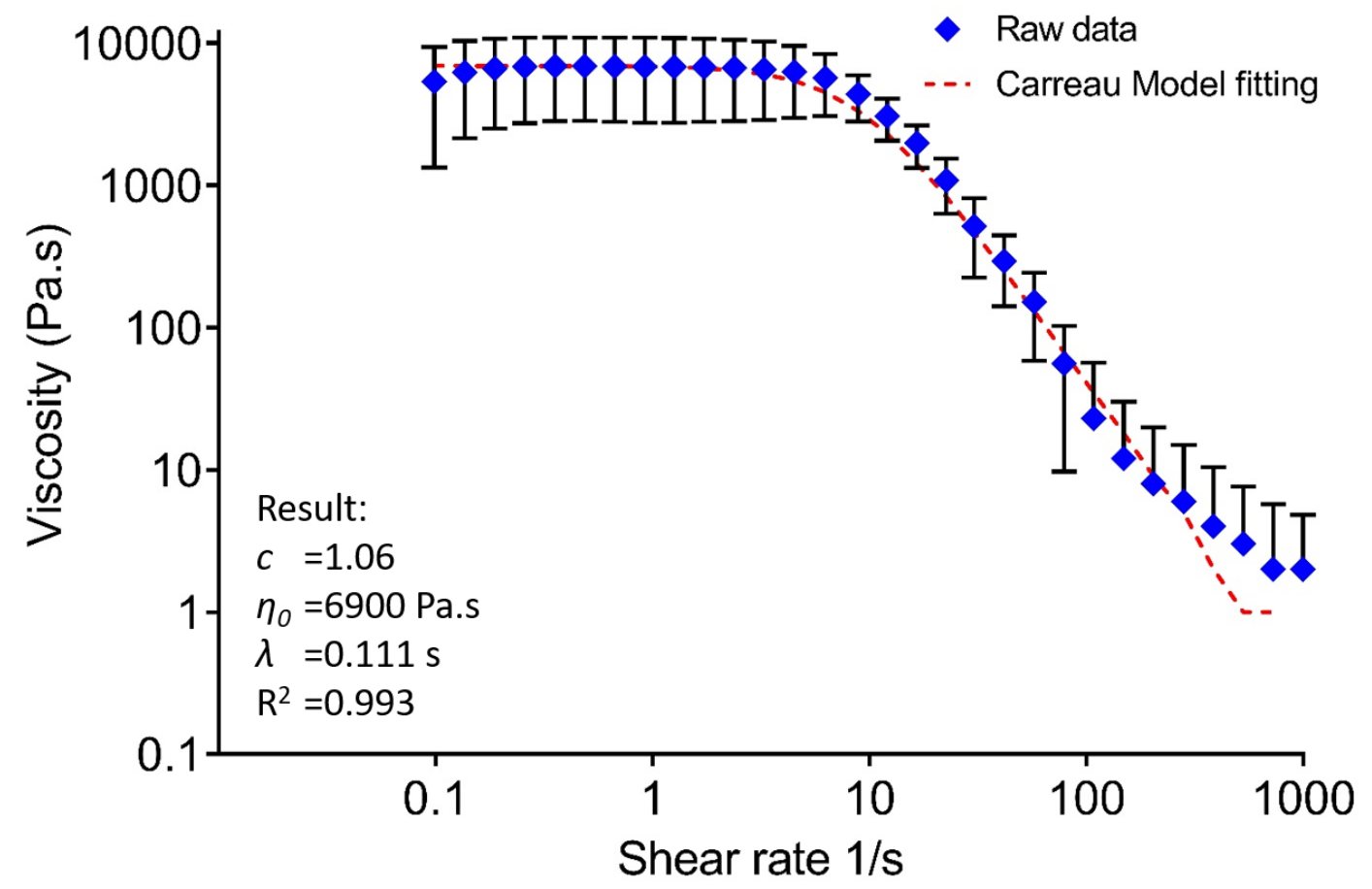

Figure 1 Raw data given by the ambient pressure viscosity measurement of neat $10 \mathrm{kDa}$ PLA (blue diamonds) is analysed by the Rheoplus software to provide a Carreau model fit (red dashed line) along with quantitative values for the zero shear viscosity, $\eta_{0}$ (Pa.s) and relaxation time, $\lambda(\mathrm{s})$. Error bars represent \pm 1 standard deviation from the mean. $T=80^{\circ} \mathrm{C}$. Note that due to the log scale of the axis, error bars which give negative values are not present. Also during shear thinning and at low viscosity the measurement is inherently subject to large errors. 


\section{Saturation time}

The time taken for each sample to become saturated with $\mathrm{CO}_{2}$ and reach a viscosity minimum varied with increasing PEG content. In order to calculate this time, viscosity versus time was plotted from the values determined from the Carreau model. These plots were then fitted to an empirical function, given in equation 2 (Figure 2). This represents a transition from a linear drop in log viscosity $(\eta)$ with time $(t)$ for short times to a constant saturation viscosity $\left(\eta_{\text {sat }}\right)$ at longer times. In order to obtain the transition time at which saturation viscosity is reached $\left(t_{\text {sat }}\right)$, the time at the intercept of the two linear segments is calculated from equation 3.

$$
\begin{aligned}
& \eta=10^{\left(t^{*}-t\right) m}+\eta_{\text {sat }} \\
& t_{\text {sat }}=t^{*}-\frac{1}{m}\left(\log _{10} \eta_{\text {sat }}\right)
\end{aligned}
$$

Here $t^{*}$ is an interim parameter corresponding to the time at which $\log _{10}\left(\eta-\eta_{\text {sat }}\right)=0$ and $m$ is the gradient of the drop in log viscosity with time. 


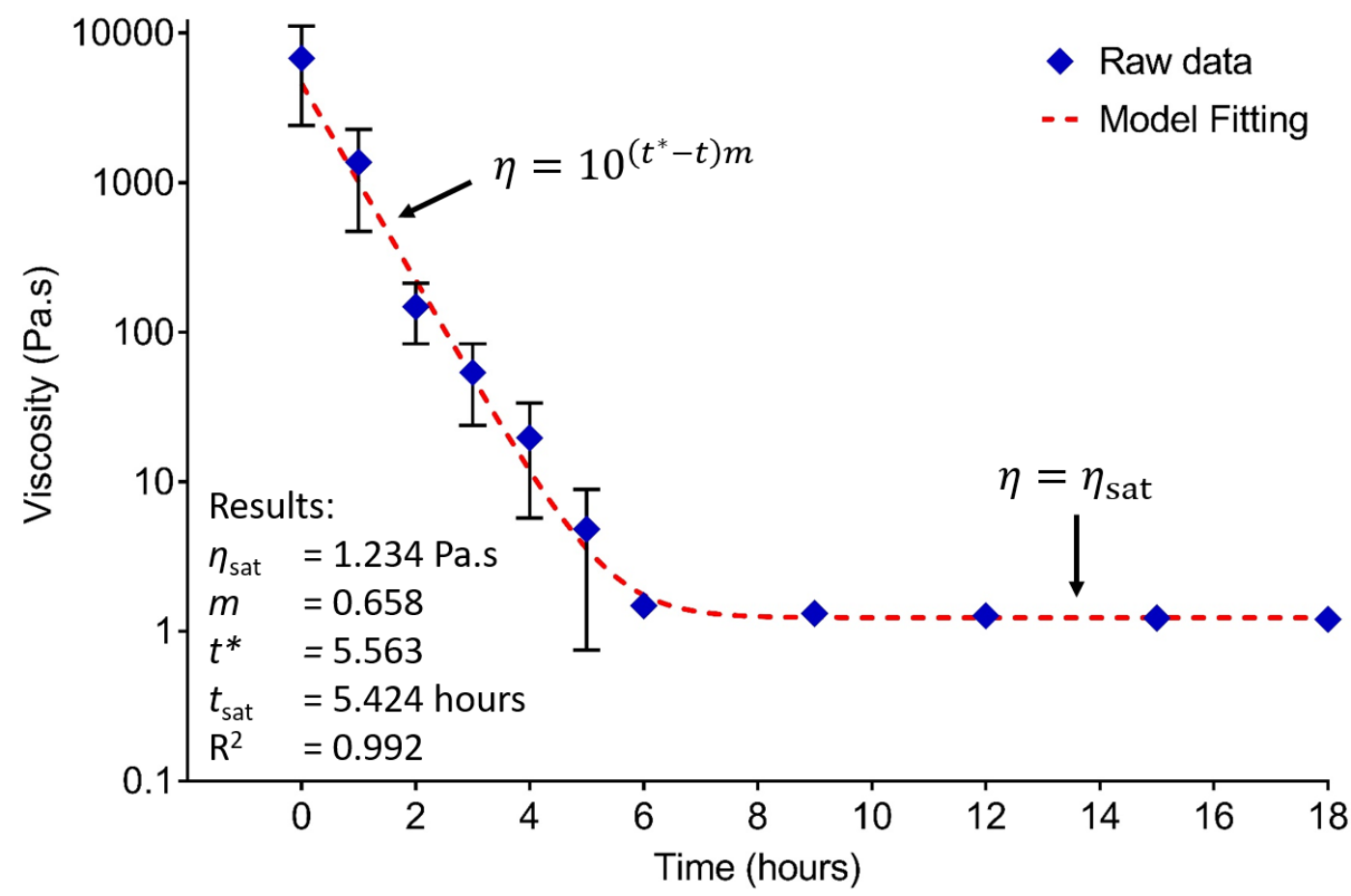

Figure 2 Raw data of the zero shear viscosity vs time (blue diamonds) is fitted to equation 2 (red dashed line). From this it is possible to determine the saturation viscosity of the sample ( $\left.\eta_{\text {sat }}(\mathrm{Pa} . \mathrm{s})\right)$, the gradient of the slope $(m)$ and the saturation time, $\left(t_{\text {sat }}\right.$ (hours $\left.)\right)$, along with the $R^{2}$ value. Error bars represent \pm 1 standard deviation from the mean. $T=80^{\circ} \mathrm{C}$. 


\section{Results}

\section{PLA}

The viscosities of a commercial grade $10 \mathrm{kDa}$ PLA and a synthesised $5 \mathrm{kDa}$ PLA were investigated at ambient pressure $\left(p_{\text {amb }}\right)$ and 140 bar $\left(T=80^{\circ} \mathrm{C}\right)$ in order to assess the effect of $\mathrm{CO}_{2}$ on the neat polymer (Figure 3). A significant decrease in viscosity was observed for the $10 \mathrm{kDa}$ PLA from 6800 Pa.s to 1 Pa.s, after soaking with $\mathrm{CO}_{2}$ in the rheometer for 18 hours to ensure complete saturation with $\mathrm{CO}_{2}$. The zero shear viscosity of the lower molecular weight 5 kDa PLA (1200 Pa.s) at ambient pressure and under $\mathrm{scCO}_{2}$ was significantly lower than that of the original $10 \mathrm{kDa}$ PLA (6800 Pa.s). This is because lower molecular weight polymers have fewer chain entanglements than their higher molecular weight counterparts resulting in materials which flow more easily with lower viscosity.

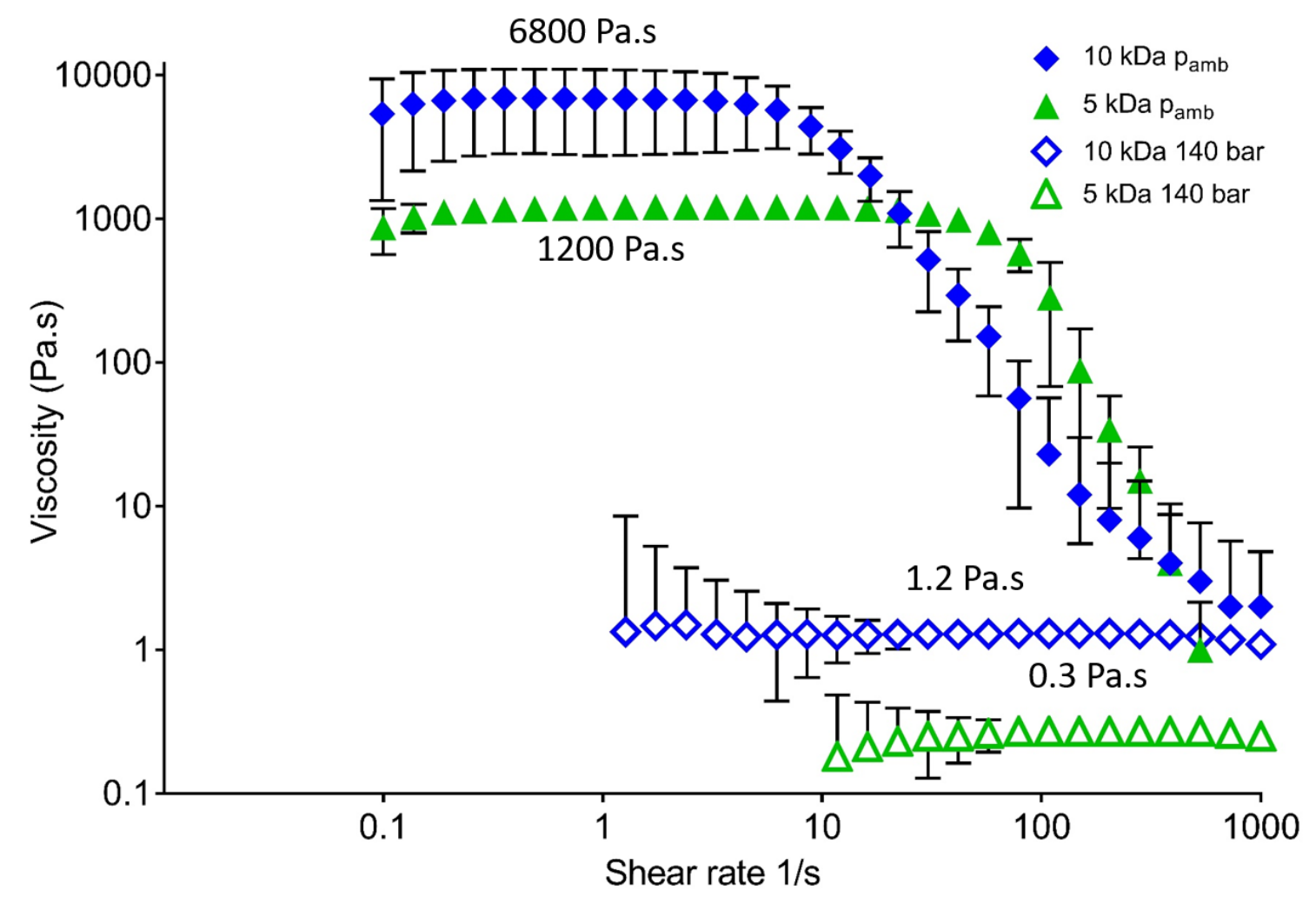

Figure 3 Viscosity of $10 \mathrm{kDa}$ PLA and $5 \mathrm{kDa}$ PLA in the presence of $\mathrm{CO}_{2}$ at 140 bar, showing a huge reduction from that at ambient pressure $\left(p_{a m b}\right)$ without $\mathrm{CO}_{2}$. The viscosity of the $5 \mathrm{kDa}$ PLA is significantly lower than that of the $10 \mathrm{kDa}$ PLA. Error bars represent \pm 1 standard deviations from the mean. $T=80^{\circ} \mathrm{C}$

Zero shear viscosity scales as either the square or the $3.4^{\text {th }}$ power of molecular weight $(M)$, depending on whether the chains are entangled or not.[45] For PLA, the entanglement 
molecular weight $\left(M_{e}\right)$ has been reported as $\sim 9 \mathrm{kDa}$. [46] In our case we find that the viscosity correlates to $M^{2.3 \pm 1.0}$. Given that $\mathrm{M}$ is shorter than the critical molecular weight $\left(M_{\mathrm{c}}\right)$, typically taken as the point at which the system becomes fully entangled $\left(M_{c} \sim 2 M_{e}\right),[47]$ the lower value we observe is in line with the expected viscosity correlation to $\sim M^{2}$. Once the polymer is saturated with $\mathrm{CO}_{2}$, the viscosity becomes proportional to $M^{1.6 \pm 0.8}$, which is still close to the expected $\sim M^{2}$, given the additional uncertainty arising from the measurement of very low viscosities and the possible solvent effects of $\mathrm{CO}_{2}$ on the entanglement length of the polymer.[48]

\section{Effect of additives on viscosity}

The viscosity of a series of PEG/PLA blends was measured at ambient pressure and 140 bar and the results compared with the neat polymers. Samples were weighed into vials and mechanically mixed before being loaded into the measuring cell. This approach was intended to give an indication of how PEG could affect the processing parameters. An additional PLA only, control blend (10 wt.\% 5 kDa PLA with 90 wt.\% 10 kDa PLA (PLA $\left.10: P L A_{10} 90\right)$ ) was prepared and its viscosity was compared to that of 10 wt.\% PEG blend (PEG $10: P_{10}$ 1090). This experiment was added as there have been recent reports of the use of short chain PLA oligomers as plasticisers to provide a viscosity reduction.[49]

Initially the measurements at $80^{\circ} \mathrm{C}$ and ambient pressure were performed and increasing the PEG content (wt. \%) resulted in a decrease in viscosity (Figure 4). This confirmed that PEG can be used as a processing aid for polymer melt systems, by lowering the overall viscosity of the system. These data are in agreement with other results reported in the literature.[43] Even at relatively low concentrations of 5 wt. \%, a decrease in shear viscosity of $64 \%$ can be seen from 6800 Pa.s for $P L A_{10} 100$ down to 2400 Pa.s for $P_{E G} 5: P L A_{10} 95$. This gives a clear indication that PEG does plasticise PLA, especially since relatively small quantities resulted in a considerable reduction in viscosity. With the addition of 10 wt\% PEG a viscosity decrease of 95\% was observed, to 400 Pa.s for PEG $10: \mathrm{PLA}_{10} 90$.

Table 2 also shows the effect of the addition of PLA (10 wt\% $5 \mathrm{kDa}$ ) instead of PEG (10 wt\% 5 $\mathrm{kDa}$ ) to the same $10 \mathrm{kDa}$ PLA (PLA $\left.10: \mathrm{PLA}_{10} 90\right)$. These data show that the addition of a small amount of a shorter chain homopolymer (PLA) has negligible effect upon the viscosity. By contrast, the addition of $5 \mathrm{kDa}$ PEG, significantly lowers the viscosity, demonstrating that it is 
not the presence of short chains per se that reduces the viscosity of the blend, but the plasticising effect of the PEG molecules themselves.

When the samples were pressurised with $\mathrm{CO}_{2}$ at 140 bar and $80{ }^{\circ} \mathrm{C}$ a significant decrease in viscosity (greater than $50 \%$ ) was observed in all cases after only 1 hour of shearing at $10 \mathrm{~s}^{-1}$ (Figure 4) (Table S3 for absolute values). After saturation with $\mathrm{CO}_{2}$, addition of PEG to the PLA resulted in minimal further viscosity reductions compared to those observed at ambient pressure (Figure 4). However, a clear reduction in the time taken to achieve saturation could prove to be a benefit for processes that require fast liquefaction of the polymer at similar temperatures.

Measurement of the viscosity after venting was made to determine whether processing with $\mathrm{CO}_{2}$ has any irreversible influence on the final product. All blends were found to recover their viscosity relatively well (Figure 4) confirming that all $\mathrm{CO}_{2}$ is removed on depressurisation and that blends recover their original characteristics. There are some slight differences in viscosities before and after processing but these are not thought to be significant given the errors associated with such rheological measurements. It is not thought that thermal degradation as a result of being held at $80^{\circ} \mathrm{C}$ for such a long time ( $>24$ hours) should have a significant effect, but this cannot be completely excluded. In a production environment, it is unlikely that the blends would need to be exposed for such a significant time period to reach their minimum viscosities. In general, processing with $\mathrm{CO}_{2}$ shows no significant lasting or detrimental effects on the final product properties, and this is in agreement with previous results in the literature.[38] 


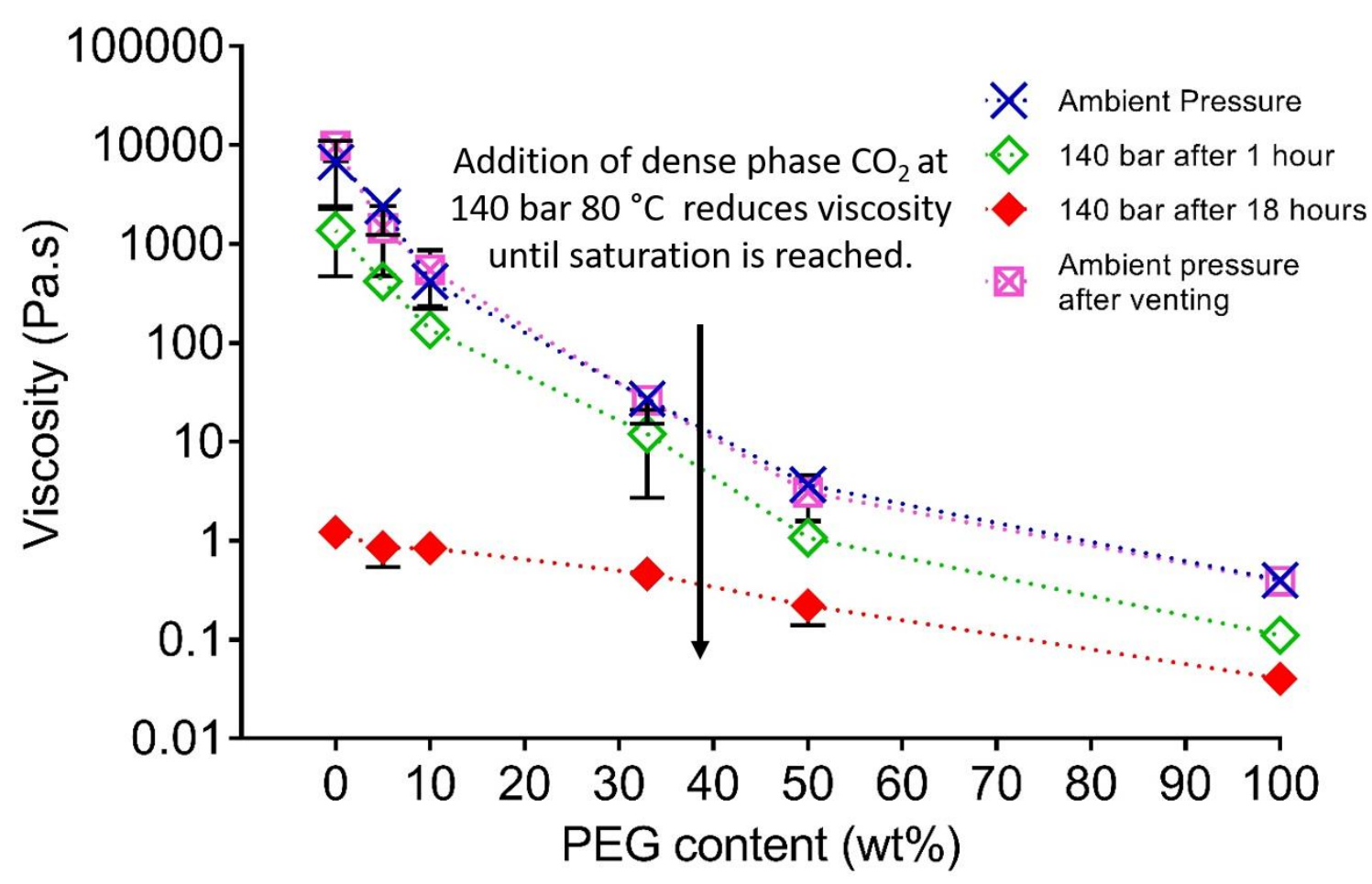

Figure 4 Viscosity of PLA-PEG blends measured at ambient pressure, and after soaking in $\mathrm{CO}_{2}$ for 1 and 18 hours at 140 bar pressure. Error bars represent \pm 1 standard deviations from the mean $\left(T=80^{\circ} \mathrm{C}\right)$.

Table 2 At ambient pressure the viscosity of $10 \mathrm{kDa}$ PLA is significantly reduced by the presence of 10 wt\% 5 kDa PEG, whereas no significant difference is seen by the addition of $10 \mathrm{wt} \% 5 \mathrm{kDa}$ PLA. Error represents \pm 1 standard deviation from the mean $\left(T=80^{\circ} \mathrm{C}\right)$.

\begin{tabular}{|c|c|c|}
\hline \multirow{2}{*}{ Sample } & $\begin{array}{c}\text { Zero shear viscosity } \\
\text { at } \boldsymbol{P}_{\boldsymbol{a m b}}\end{array}$ & \multirow{2}{*}{$\begin{array}{c}\text { \% Decrease } \\
\text { relative to } \\
\text { PLA }_{\mathbf{1 0}} \mathbf{1 0 0}\end{array}$} \\
\cline { 2 - 2 } & Average \pm SD (Pa.s) & \\
\hline $\mathrm{PLA}_{10} 100$ & $6800 \pm 4300$ & -10.70 \\
$\mathrm{PLA}_{5} 10: \mathrm{PLA}_{10} 90$ & $7500 \pm 1100$ & 93.82 \\
\hline $\mathrm{PEG}_{5} 10: \mathrm{PLA}_{10} 90$ & $400 \pm 200$ & 93.80 \\
\hline
\end{tabular}

All blends were left for 18 hours to ensure complete $\mathrm{CO}_{2}$ saturation and to enable a more accurate comparison. It should be noted that this timescale is merely a function of the limited surface area of the polymer that is accessible to $\mathrm{ScCO}_{2}$ inside the rheometer. In our view cells we can observe that the polymers are fully liquefied within minutes and at pressures as low as 20 bar.[50] As the PEG content (wt \%) increased, the time taken for the samples to reach viscosity equilibrium decreased, from approximately 5 hours for PLA $A_{10} 100$ to less than 1 hour for $\mathrm{PEG}_{5} 100$ where due to the nature of the experiment it is not possible to calculate an exact value as the sample has reached its saturation viscosity before the first measurement is 
performed at 1 hour (Figure 5). At $80^{\circ} \mathrm{C}$ both PEG and PLA are in their equilibrium melt states given that PEG has a $T_{m}$ of $60^{\circ} \mathrm{C}$ and amorphous PLA has a $T_{g}$ of $50^{\circ} \mathrm{C}$, but the greater mobility of the PEG molecules substantially reduces the relaxation time of the PLA molecules at the same temperature. Therefore $\mathrm{CO}_{2}$ penetration can occur more quickly, reducing the viscosity further and reaching equilibrium in a shorter time. It follows that as PEG content increases, mobility of the remaining PLA chains will also increase, and even shorter saturation times are observed.

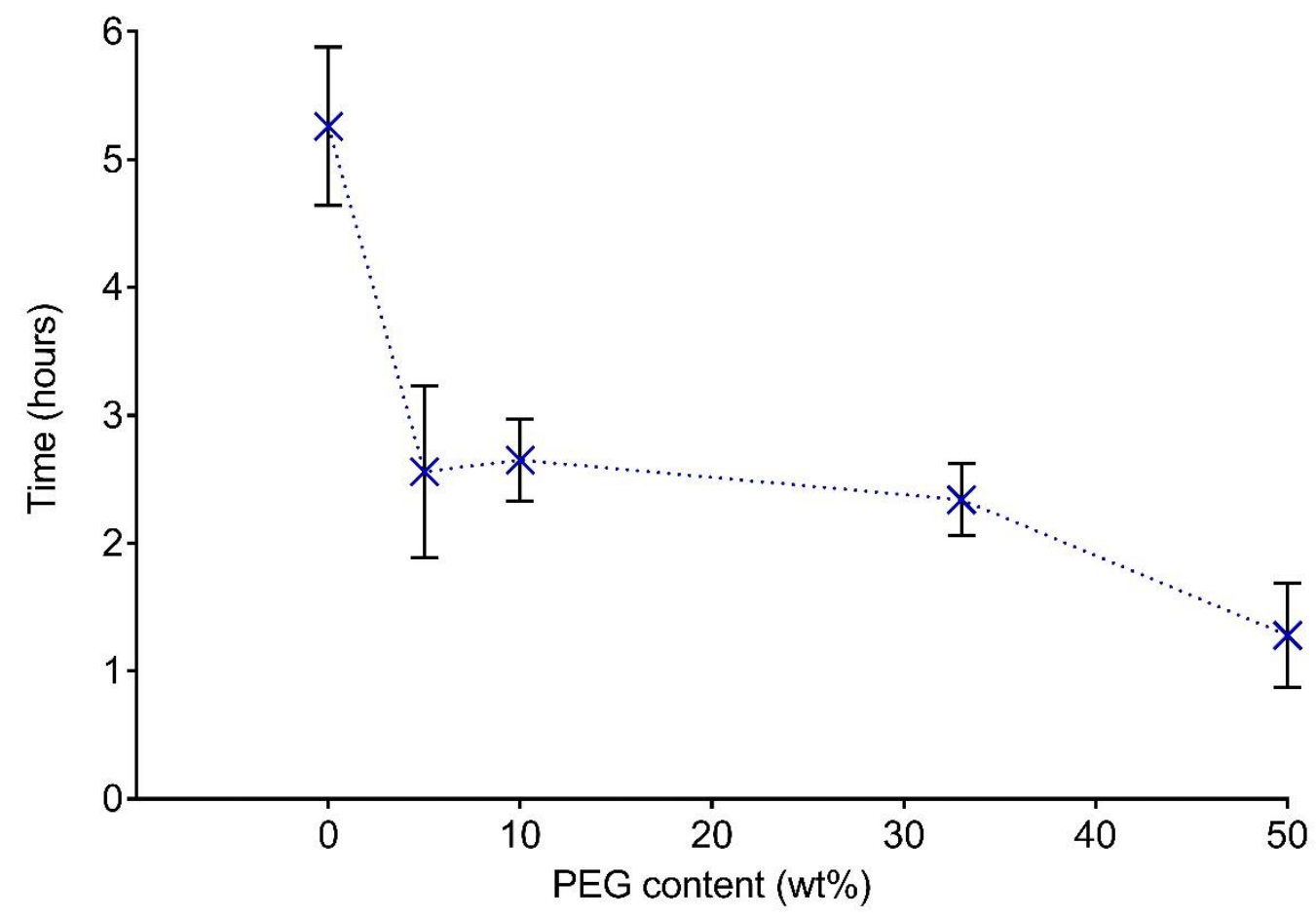

Figure 5 In the presence of 140 bar $\mathrm{CO}_{2}$, the time taken for each sample to be saturated with $\mathrm{CO}_{2}$ and to reach the viscosity equilibrium decreases as PEG content increases. Error bars represent \pm 1 standard deviations from the mean.

\section{PEG- $b-P L A$}

Block copolymers of PEG-b-PLA were manufactured by ring opening polymerisation (ROP) in $\mathrm{CO}_{2}$ in order to compare the viscosity of the blocks to those of physical blends of similar PEG:PLA compositions (Figure 6). A 5 kDa PEG macro-initiator was used in the synthesis of two block copolymers yielding a copolymer with a 5:5 PEG:PLA ratio (PEG $-b-$ PLA $_{5}$ ) and another with a 5:10 PEG:PLA ratio ( $\left.\mathrm{PEG}_{5}-b-\mathrm{PLA}_{10}\right)$ (See SI for further information). In order to keep the weight fractions of the respective polymers constant, the viscosity of the $\mathrm{PEG}_{5}-b$ - 
$\mathrm{PLA}_{5}$ copolymer was compared to that of the 50 wt\% $10 \mathrm{kDa}$ PEG blend (PEG $1050: \mathrm{PLA}_{10} 50$ ) while the $\mathrm{PEG}_{5}-b-\mathrm{PLA}_{10}$ copolymer was compared to the 33 wt\% PEG (PEG $\left.33: \mathrm{PLA}_{10} 67\right)$. The viscosities of both of the block copolymers were found to be significantly reduced in comparison to the neat PLA (PLA 10100$)$; from 6800 Pa.s to 5.6 Pa.s for PEG $\mathrm{PG}_{5}-b-\mathrm{PLA} \mathrm{A}_{5}$ and to 44 Pa.s for $\mathrm{PEG}_{5}-b-\mathrm{PLA}_{10}$ (Figure 6). However, the observed viscosity reduction for $\mathrm{PEG}_{5}-b-\mathrm{PLA}_{10}$ is not as large as that observed for the weight-equivalent blend PEG $333:$ PLA $_{10} 67$, which exhibited a viscosity of 27 Pa.s. This blend is a mixture of longer, less mobile PLA chains with shorter, highly mobile PEG chains. By contrast, the block copolymer is a covalently linked analogue and clearly some of the degrees of freedom of the PEG chains are lost once it is bonded to the PLA (Figure 7). This results in a higher viscosity for the block copolymer, but one that is still noticeably lower than that of the neat PLA. The overall molecular weight of the copolymer ( $15 \mathrm{kDa})$ is another contribution to the elevated viscosity, being longer than both the neat PLA (10 kDa) and PEG (5 kDa).

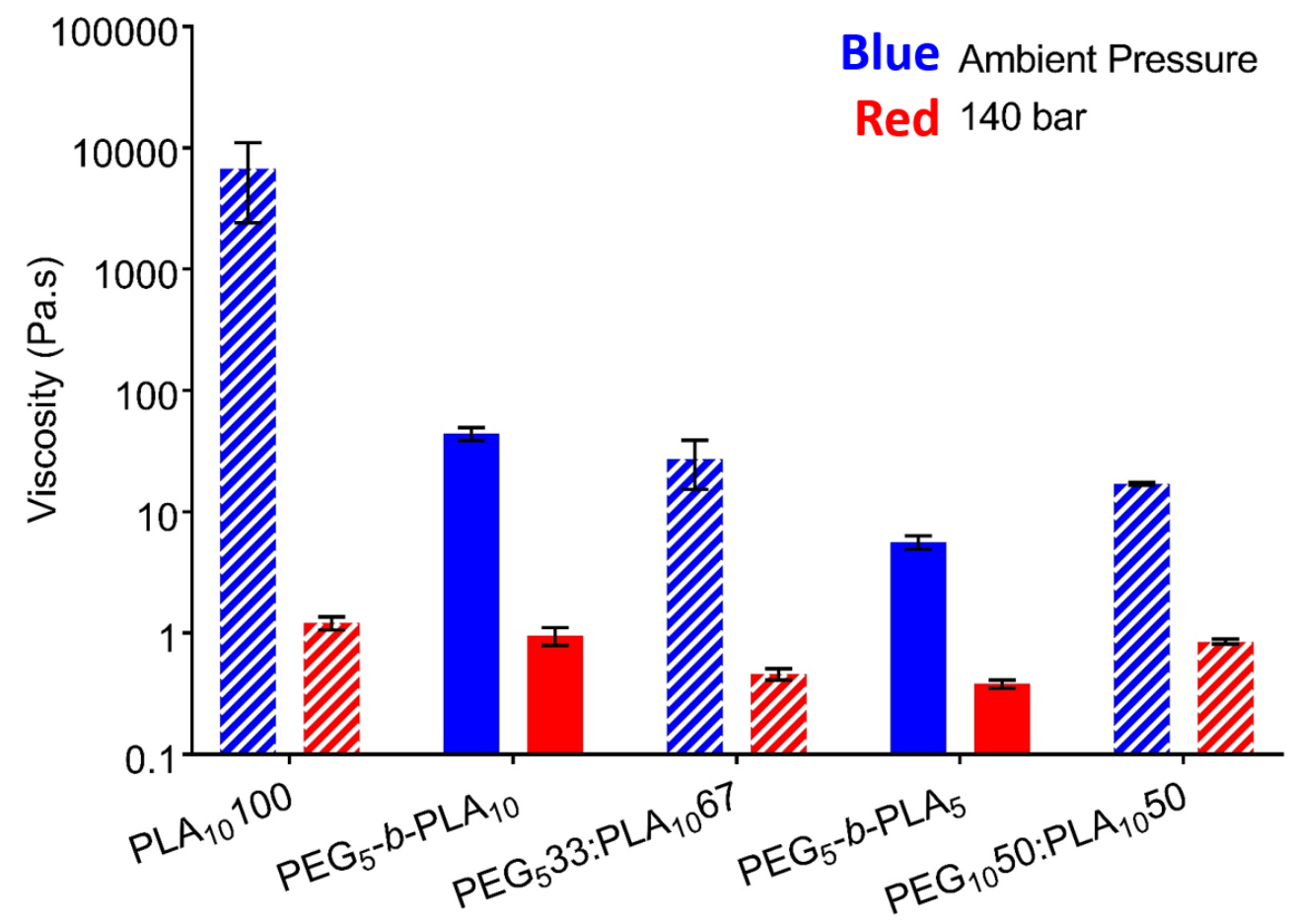

Figure 6 Comparison of the viscosity of PEG/PLA blends and PEG- $b$-PLA copolymers at ambient pressure and after 18 hours in $\mathrm{CO}_{2}$ at 140 bar pressure. The hatched bars represent the blends while the block colours represent the block copolymers. Error bars represent \pm 1 standard deviation from the mean $\left(T=80^{\circ} \mathrm{C}\right)$. 
When the viscosities of the block PEG $5-b-P_{2} A_{5}$ (5.6 Pa.s) and blend PEG $1050: P L A_{10} 50$ (17 Pa.s) are compared to one another a reversal of this trend is observed. In this instance the block copolymer has the same molecular weight as the two homopolymer components of the blend (10 kDa). In this case we see that the block copolymer has a significantly lower viscosity than the blend. This can be rationalised by the fact that the block copolymer consists of a less mobile but short ( $5 \mathrm{kDa}$ ) PLA chain covalently bound to a highly mobile PEG chain (also $5 \mathrm{kDa}$ ) (Figure 7). By contrast, the blend can be described as a mixture of individual blocks but both have a full $10 \mathrm{kDa}$ chain length. In this case, the observed viscosity reflects the larger molecular weight of the individual polymer chains of the blend (10 kDa) in comparison to the molecular weight of the separate blocks and shows a dominance of the PLA. This can also be reflected by looking carefully at the viscosity of the corresponding PLA chains. The shorter 5 kDa PLA homopolymer (PLA 100$)$ has a viscosity of only 1200 Pa.s, whilst the 10 kDa PLA (PLA 10100$)$ homopolymer is much larger, 6800 Pa.s. Similarly, chain length strongly determines the viscosities of the PEG homopolymer chains with 5 kDa PEG showing a very low viscosity of 0.4 Pa.s whereas the $10 \mathrm{kDa}$ PEG is much higher; 3.5 Pa.s.

\begin{tabular}{|c|c|c|c|c|c|c|c|}
\hline Sample & Schematic & $\begin{array}{c}\text { Molecular } \\
\text { weight }\end{array}$ & $\begin{array}{c}\text { Viscosity } \\
\left(p_{\text {amb }}\right)\end{array}$ & Sample & Schematic & $\begin{array}{l}\text { Molecular } \\
\text { weight }\end{array}$ & $\begin{array}{c}\text { Viscosity } \\
\left(\boldsymbol{p}_{\text {amb }}\right)\end{array}$ \\
\hline $\mathrm{PLA}_{10} 100$ & תนก & $10 \mathrm{kDa}$ & 6800 Pa.s & PEG $_{10} 100$ & $\sim \sim \sim \sim \sim$ & $10 \mathrm{kDa}$ & 3.5 Pa.s \\
\hline $\mathrm{PLA}_{5} 100$ & n & $5 \mathrm{kDa}$ & 1200 Pa.s & PEG $_{5} 100$ & $\sim \sim$ & $5 \mathrm{kDa}$ & 0.4 Pa.s \\
\hline $\mathrm{PEG}_{5}-b-\mathrm{PLA}_{10}$ & $\sim \sim \Omega \sim \Omega r$ & $15 \mathrm{kDa}$ & 44 Pa.s & $\mathrm{PEG}_{5}-b-\mathrm{PLA}_{5}$ & $\sim \sim \Omega$ & $10 \mathrm{kDa}$ & 5.6 Pa.s \\
\hline PEG $_{5} 33:$ PLA $_{10} 67$ & ח & $\begin{array}{c}10 \mathrm{kDa} \text { PLA } \\
+ \\
5 \mathrm{kDa} \text { PEG }\end{array}$ & 27 Pa.s & $\mathrm{PEG}_{10} 50: \mathrm{PLA}_{10} 50$ & ) & $\begin{array}{c}10 \mathrm{kDa} \text { PLA } \\
+ \\
10 \mathrm{kDa} \text { PEG }\end{array}$ & 17 Pa.s \\
\hline
\end{tabular}

Figure 7 Series of schematics depicting the various block copolymers and their comparable blends, along with the neat polymers for reference. PLA is shown as blue highly coiled chains whereas PEG is the less coiled red chains. Viscosity and molecular weights are also given.

For the purpose of improving process ability, both blends and block copolymers significantly reduce the viscosity of PLA and therefore either could be employed. The choice of which to use will depend on the final application of the product. For example a blend will have hydrophilic channels enhancing hydrolytic degradation which is important for drug delivery applications. On the other hand block copolymers could produce micellar like materials with improved solubility. 


\section{Conclusions}

Our high pressure rheological data confirm that a combination of PEG and $\mathrm{CO}_{2}$ can improve dramatically the ability to process the widely used poly(D,L Lactide) polymer. Not only are process temperature and melt viscosity significantly lowered, but we also show that PEG reduces the diffusion time of $\mathrm{CO}_{2}$ through the melt. Our data allow quantification of the process improvements that $\mathrm{scCO}_{2}$ could bring and also have shown for the first time the effect of PEG in both PEG/PLA blends and in block copolymers. Using rheology we also confirmed that after venting, all the $\mathrm{CO}_{2}$ is removed and there are no lasting post processing effects on viscosity. These data will be exploited in the future to open up a wider range of drug delivery devices and tissue engineering materials based upon commercially acceptable biodegradable polymers.

\section{Acknowledgements}

We thank the MRC for a CASE Award (MR/L015706/1) to KJP. We are indebted to Richard Wilson, Peter Fields, Mark Guyler and Martin Dellar for their vital technical input. We are grateful also for the input of our colleagues at Critical Pharmaceuticals Ltd, in particular Dr Anjumn Shabir-Ahmed and Dr Andrew Naylor. 


\section{Supplementary Information}

\section{Synthesis}

Both the block copolymers and the neat $5 \mathrm{kDa}$ PLA were synthesised from a racemic mix of $\mathrm{D}$, L-lactide using ring opening polymerisation in $\mathrm{CO}_{2}$, with a mono-functional PEG macroinitiator for the blocks and benzyl alcohol for the PLA alongside the standard tin(II) 2ethylhexanoate $\left(\mathrm{Sn}(\mathrm{oct})_{2}\right)$ catalyst. Prior to synthesis the monomer, initiator and catalyst were dried overnight in a vacuum oven at $25^{\circ} \mathrm{C}$ to minimise the presence of water.

Lactide, initiator and $\mathrm{Sn}(\mathrm{oct})_{2}$ were weighed into the autoclave and purged with $\mathrm{CO}_{2}$ for 5-10 minutes in order to remove any oxygen (see Table S1 for molar ratios). The vessel was then sealed and the pressure increased to 55 bar and stirring started. The temperature was then set to $120^{\circ} \mathrm{C}$, and the pressure topped up to 240 bar. The synthesis proceeded for 1 hour after which the autoclave was cooled on ice until it reached a temperature less than $25^{\circ} \mathrm{C}$ and vented. Following this, samples were purified using $\mathrm{CO}_{2}$ extraction where the sample is exposed to a flow of $\mathrm{CO}_{2}$ at $45^{\circ} \mathrm{C}$ and 240 bar for 2 hours in the presence of a small amount of ethanol (2 mL).[51] Samples were then characterised using DSC, NMR and GPC.

Table S1 Molar ratios used for synthesis of PLA and PEG- $b$-PLA copolymers.

\begin{tabular}{|c|c|c|c|c|c|}
\hline & \multicolumn{4}{|c|}{ Molar ratio } & \multirow{2}{*}{$\begin{array}{c}\text { Target PLA Mwt } \\
(\mathrm{kDa})\end{array}$} \\
\hline & Lactide & $\operatorname{Sn}(o c t)_{2}$ & 5 kDa PEG & Benzyl Alcohol & \\
\hline $\mathrm{PLA}_{5} 100$ & 35 & 0.1 & I & 1 & 5 \\
\hline $\mathrm{PEG}_{5}-b-\mathrm{PLA}_{5}$ & 35 & 0.1 & 1 & I & 5 \\
\hline $\mathrm{PEG}_{5}-b-\mathrm{PLA}_{10}$ & 70 & 0.1 & 1 & I & 10 \\
\hline
\end{tabular}


Table S2 Details of polymers synthesised by ROP in $\mathrm{ScCO}_{2}$.

\begin{tabular}{|c|c|c|c|c|c|c|c|c|}
\hline & $\begin{array}{c}\text { PEG M } \\
(\mathrm{Da})^{\mathrm{a}}\end{array}$ & $\begin{array}{c}\text { PLA M }_{n} \\
(\mathrm{Da})^{\mathrm{a}}\end{array}$ & $\begin{array}{c}\text { Total Mn }_{n} \\
(\mathrm{Da})^{\mathrm{a}}\end{array}$ & $\begin{array}{c}\mathrm{M}_{\mathrm{n}} \\
(\mathrm{Da})^{\mathrm{b}}\end{array}$ & $\begin{array}{c}\mathrm{M}_{\mathrm{w}} \\
(\mathrm{Da})^{\mathrm{b}}\end{array}$ & $\mathrm{Ð}^{\mathrm{b}}$ & $\begin{array}{c}\mathrm{T}_{\mathrm{g}} \\
\left({ }^{\circ} \mathrm{C}\right)^{\mathrm{c}}\end{array}$ & $\begin{array}{c}\mathrm{T}_{\mathrm{m}} \\
\left({ }^{\circ} \mathrm{C}\right)^{\mathrm{c}}\end{array}$ \\
\hline $\mathrm{PLA}_{5} 100$ & $/$ & 5200 & 5200 & 5500 & 6300 & 1.14 & 38 & $/$ \\
\hline PEG $_{5}-b-\mathrm{PLA}_{5}{ }^{*}$ & 5300 & 4600 & 10000 & 7500 & 8600 & 1.15 & $/$ & 50 \\
\hline PEG $_{5}-b-\mathrm{PLA}_{10}{ }^{*}$ & 5200 & 9400 & 14600 & 10500 & 12100 & 1.16 & $/$ & 48 \\
\hline
\end{tabular}

* dn/dc values for block copolymers calculated from NMR (Equation S1). (a) Calculated from ${ }^{1} \mathrm{H}$ NMR. (b) Determined from triple detection GPC. (c) Obtained from DSC.

\section{Analytical Methods}

DSC

Differential scanning calorimetry (DSC) was performed on a TA-Q2000 (TA instruments) DSC calibrated with an indium standard under nitrogen flow. 1-3 mg of sample was weighed into a T-zero sample pan (TA instruments) while a second reference T-zero pan remained empty. Both pans were heated at $10^{\circ} \mathrm{C} / \mathrm{min}$, from $-90^{\circ} \mathrm{C}$ to $120^{\circ} \mathrm{C}$. Three samples of each polymer were analysed with two heating cycles per sample in order to erase any thermal history of the individual samples and the results calculated as an average of transitions from the second cycle.

GPC

Molecular weights of the polymers were determined using an Agilent 1260 infinity multidetector GPC/SEC system with Wyatt Optilab light scattering. Columns consisted of 2 Agilent PLGEL $5 \mu \mathrm{m}$ Mixed D $(7.5 \mathrm{~mm}$ X $300 \mathrm{~mm})$ columns and a PLGEL $5 \mu \mathrm{m}$ guard column $(7.5 \mathrm{~mm} \times 50 \mathrm{~mm})$ in THF at $1 \mathrm{~mL} / \mathrm{min}$ using differential index of refraction values $(\mathrm{dn} / \mathrm{dc})$ of $0.042 \mathrm{~mL} / \mathrm{g}$ for PLA[52] and $0.067 \mathrm{~mL} / \mathrm{g}$ for PEG.[53] For the block copolymers $\mathrm{dn} / \mathrm{dc}$ was calculated using the weight percent as determined from NMR.[54]

NMR

${ }^{1} \mathrm{H}$ NMR spectra were obtained by dissolving the samples in deuterated chloroform and analysing them using a Bruker DPX $300 \mathrm{MHz}$ spectrometer. The NMR spectra were used to calculate conversion and molecular mass of the polymers and the $\mathrm{dn} / \mathrm{dc}$ values of the block copolymers for GPC. The dn/dc value of a block copolymer can be calculated from the known 
$\mathrm{dn} / \mathrm{dc}$ values of the individual blocks where $x$ is the weight fraction of PEG and $y$ is the weight fraction of PLA from the NMR as shown in equation S1.[54]

$$
\frac{d n}{d c}=x\left(\frac{d n}{d c}\right)_{\mathrm{PEG}}+y\left(\frac{d n}{d c}\right)_{\mathrm{PLA}}
$$

\section{$\mathrm{CO}_{2}$ soaking}

High pressure viscosity is measured over a period of 18 hours to ensure all samples experience the same soaking regime. Time to saturation varies depending on blend composition and polymer. The absolute value for viscosity at 140 bar after 18 hours, $\eta_{\text {sat }}$ is obtained using equation 2 , along with the time taken to reach saturation, $t_{\text {sat. }}$ In order to determine the average saturation viscosity, the datasets with soak times greater than the transition time, $t_{\text {sat }}$ (where the viscosity is no longer decreasing with soak time) were averaged (Figure S1).

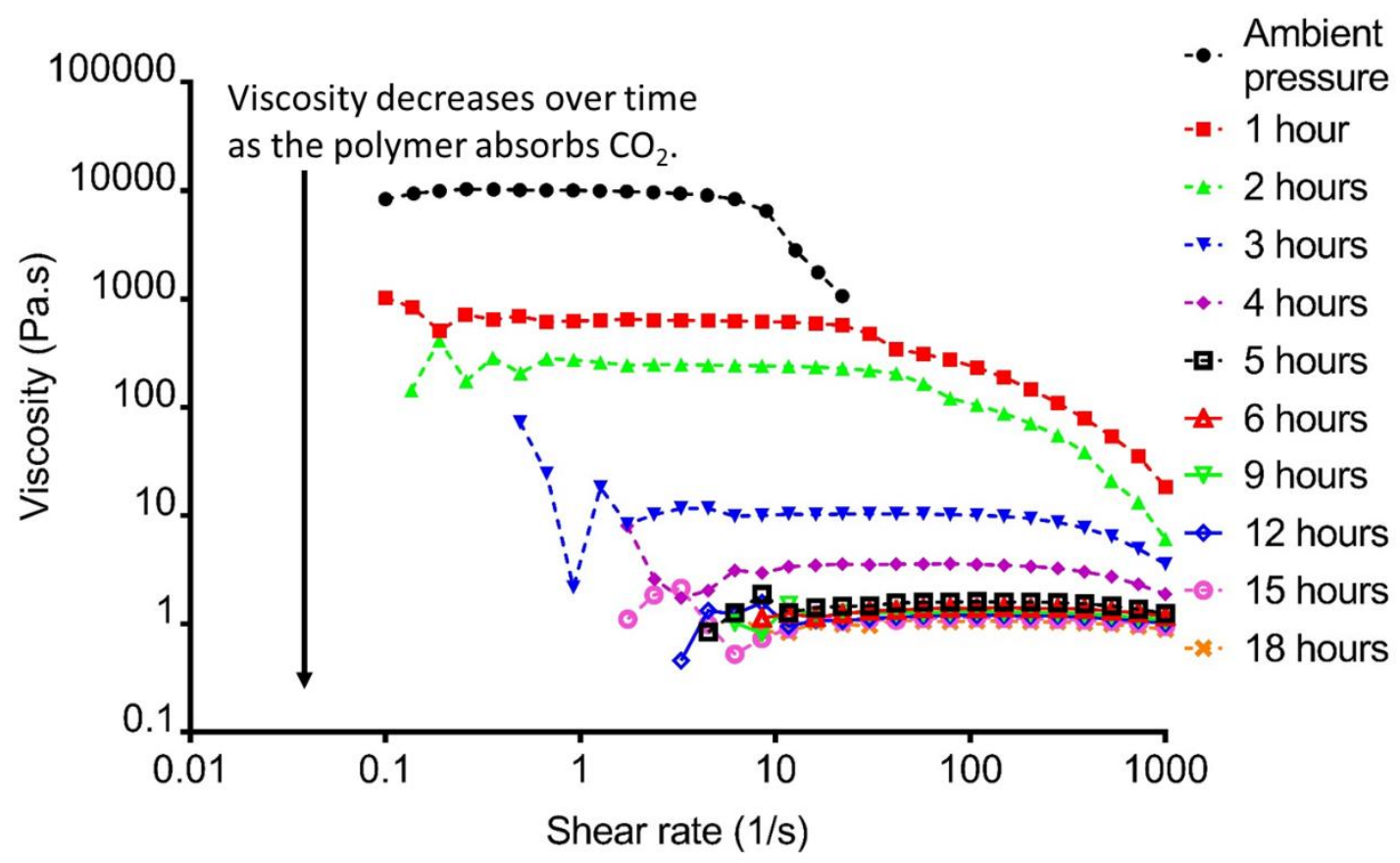

Figure S1 Viscosity of $10 \mathrm{kDa}$ PLA at various time intervals during soaking with $\mathrm{CO} 2$ at $140 \mathrm{bar}, 80^{\circ} \mathrm{C}$. Data from one sample as an example of the trend. In this example, tsat $=4.98 \mathrm{~h}$, and therefore the average saturation viscosity is calculated by taking the average of the results for 5 hours onwards. 


\section{Viscosity vs Time during $\mathrm{CO}_{2}$ soaking}

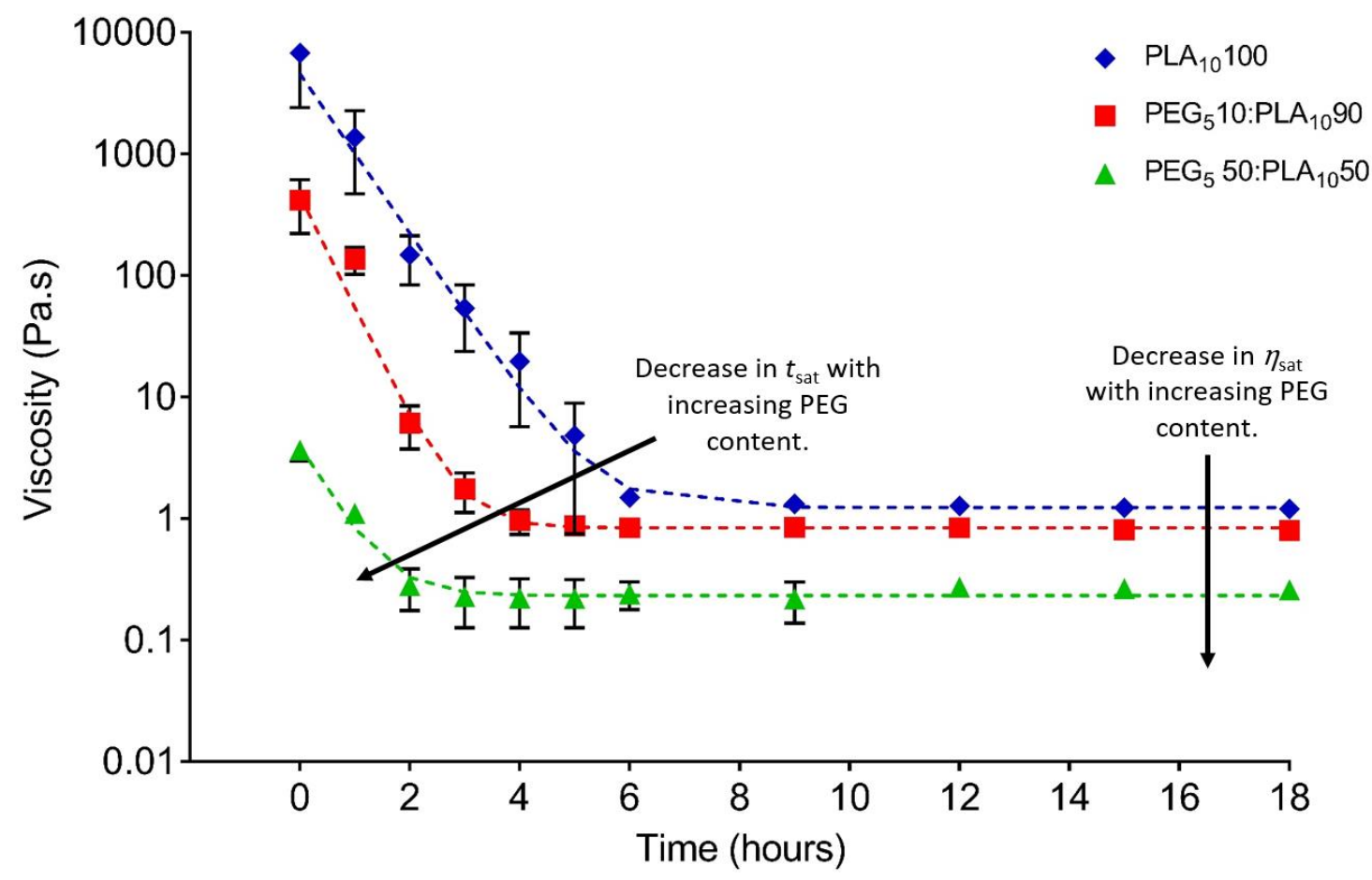

Figure S2 Selected measured viscosity versus time plots (symbols) for PEG-PLA blends and empirical functions fitted to the data (dashed lines). The functions are an appropriate fit to the datasets, and are employed to determine the saturation viscosities $\left(\eta_{\text {sat }}\right)$ and saturation times $\left(t_{\text {sat }}\right)$, given in Tables S3 and S4. Both can be seen to decrease with increasing PEG content. 
Zero shear viscosity values

Table S3 Zero shear viscosity (Pa.s) obtained using Carreau model fitting embedded in Rheoplus software $\left(\mathrm{T}=80^{\circ} \mathrm{C}\right)$.

\begin{tabular}{|c|c|c|c|c|c|c|c|c|c|c|c|c|}
\hline Sample & Av & SD & Av & 0 bar $1 \mathrm{~h}$ & $\begin{array}{c}\% \\
\text { drop } \\
\text { fom } \\
\text { pamb }\end{array}$ & Av & 0 bar & $\begin{array}{c}8 \mathrm{~h} \\
\% \\
\text { drop } \\
\text { fom } \\
\text { pamb }\end{array}$ & Av & ffter venti & $\begin{array}{l}\text { ng } \\
\% \\
\text { recovery } \\
\text { compared } \\
\text { to pamb }\end{array}$ & $\begin{array}{c}\% \\
\text { decrease } \\
\text { from } \\
\text { PLA100 }\end{array}$ \\
\hline PLA $_{10100}$ & 6758.19 & 4346.29 & 1368.76 & 898.13 & 79.75 & 1.21 & 0.15 & 99.98 & 9864.12 & 2940.90 & 145.96 & \\
\hline PEG $_{5} 5:$ PLA $_{1095}$ & 2409.27 & 1174.02 & 419.04 & 126.31 & 82.61 & 0.85 & 0.31 & 99.96 & 1446.90 & 970.09 & 60.06 & 64.35 \\
\hline $\mathrm{PEG}_{5} 10: \mathrm{PLA}_{10} 90$ & 417.61 & 195.35 & 136.30 & 33.80 & 67.36 & 0.84 & 0.13 & 99.80 & 551.05 & 316.03 & 131.95 & 93.82 \\
\hline PEG $_{53} 33:$ PLA $_{10} 67$ & 27.16 & 11.87 & 11.93 & 9.23 & 56.09 & 0.46 & 0.05 & 98.30 & 26.22 & 4.77 & 96.53 & 99.60 \\
\hline $\mathrm{PEG}_{5} 50: \mathrm{PLA}_{10} 50$ & 3.66 & 0.69 & 1.07 & 0.06 & 70.77 & 0.22 & 0.08 & 94.02 & 3.07 & 1.49 & 83.82 & 99.95 \\
\hline PEG $_{5} 100$ & 0.40 & 0.04 & 0.11 & 0.01 & 72.26 & 0.04 & 0.01 & 89.57 & 0.39 & 0.03 & 97.27 & \\
\hline $\mathrm{PEG}_{10100}$ & 3.46 & 0.21 & 1.62 & 0.11 & 53.37 & 0.63 & 0.05 & 81.82 & 2.93 & 0.24 & 84.65 & \\
\hline $\mathrm{PEG}_{10} 50$ & 17.04 & 0.59 & 7.56 & 0.55 & 55.64 & 0.85 & 0.04 & 95.00 & 14.48 & 0.46 & 85.01 & 99.75 \\
\hline $\mathrm{PEG}_{5}-b-\mathrm{PLA}_{5}$ & 5.62 & 0.71 & 1.88 & 0.26 & 66.48 & 0.38 & 0.03 & 93.26 & 6.00 & 0.67 & 106.82 & 99.92 \\
\hline $\mathrm{PEG}_{5}-b-\mathrm{PLA}_{10}$ & 44.06 & 5.33 & 14.36 & 1.76 & 67.40 & 0.95 & 0.16 & 97.84 & 41.38 & 2.61 & 93.92 & 99.35 \\
\hline PLA 100 & 1150.34 & 127.83 & 518.79 & 30.35 & 54.90 & 0.35 & 0.17 & 99.97 & 1068.33 & 95.28 & 92.87 & \\
\hline $\mathrm{PLA}_{5} 10$ & 7481.30 & 1092.63 & 1474.59 & 581.57 & 80.29 & 0.95 & 0.04 & 99.99 & 5338.41 & 1222.05 & 71.36 & -10.70 \\
\hline
\end{tabular}


Table S4 Time to saturation as determined from equation 2.

\begin{tabular}{|c|c|c|}
\hline \multirow{2}{*}{ Sample } & \multicolumn{2}{|c|}{$\begin{array}{c}\text { Time to saturation } \\
\text { (hours) }\end{array}$} \\
\hline & Average & $\begin{array}{l}\text { Standard } \\
\text { Deviation }\end{array}$ \\
\hline $\mathrm{PLA}_{10} 100$ & 5.26 & 0.62 \\
\hline $\mathrm{PEG}_{5} 5: \mathrm{PLA}_{10} 95$ & 2.56 & 0.67 \\
\hline $\mathrm{PEG}_{5} 10: \mathrm{PLA}_{10} 90$ & 2.65 & 0.32 \\
\hline PEG $_{5} 33:$ PLA $_{10} 67$ & 2.34 & 0.28 \\
\hline $\mathrm{PEG}_{5} 50: \mathrm{PLA}_{10} 50$ & 1.28 & 0.41 \\
\hline \multicolumn{3}{|l|}{$\mathrm{PEG}_{5} 100$} \\
\hline PEG $_{10100}$ & 1.25 & 0.01 \\
\hline $\mathrm{PEG}_{10} 50$ & 2.34 & 0.04 \\
\hline $\mathrm{PEG}_{5}-b-\mathrm{PLA}_{5}$ & 1.61 & 0.07 \\
\hline $\mathrm{PEG}_{5}-b-\mathrm{PLA}_{10}$ & 2.49 & 0.18 \\
\hline PLA 100 & 4.43 & 0.36 \\
\hline PLA 10 & 5.13 & 0.47 \\
\hline
\end{tabular}




\section{References}

[1] Y. Ikada, H. Tsuji, Biodegradable polyesters for medical and ecological applications, Macromolecular Rapid Communications. 21 (2000) 117-132.

[2] V.R. Sinha, A. Trehan, Biodegradable microspheres for protein delivery, Journal of Controlled Release. 90 (2003) 261-280.

[3] D.H. Lewis, Controlled Release of Bioactive Agents from Lactide/Glycolide Polymers, in: M. Chasin, R. Langer (Eds.), Biodegradable Polymers as Drug Delivery Systems, Marcel Dekker INC, New York, 1990: pp. 1-43.

[4] M.J. Whitaker, J.Y. Hao, O.R. Davies, G. Serhatkulu, S. Stolnik-Trenkic, S.M. Howdle, K.M. Shakesheff, The production of protein-loaded microparticles by supercritical fluid enhanced mixing and spraying, Journal of Controlled Release. 101 (2005) 85-92.

[5] H. Liu, J. Zhang, Research progress in toughening modification of poly(lactic acid), Journal of Polymer Science, Part B: Polymer Physics. 49 (2011) 1051-1083. doi:10.1002/polb.22283.

[6] M. Sheth, R.A. Kumar, V. Dave, R.A. Gross, S.P. McCarthy, Biodegradable polymer blends of poly(lactic acid) and poly(ethylene glycol), Journal of Applied Polymer Science. $66 \quad$ (1997) 1495-1505. doi:10.1002/(SICI)10974628(19971121)66:8<1495::AID-APP10>3.0.CO;2-3.

[7] I. Pillin, N. Montrelay, Y. Grohens, Thermo-mechanical characterization of plasticized PLA: Is the miscibility the only significant factor?, Polymer. 47 (2006) 4676-4682. doi:10.1016/j.polymer.2006.04.013.

[8] F.-J. Li, L.-C. Tan, S.-D. Zhang, B. Zhu, Compatibility, steady and dynamic rheological behaviors of polylactide/poly(ethylene glycol) blends, Journal of Applied Polymer Science. 133 (2016).

[9] T. Nazari, H. Garmabi, Polylactic acid/polyethylene glycol blend fibres prepared via melt electrospinning: effect of polyethylene glycol content, Micro \& Nano Letters. 9 (2014) 686-690. doi:DOI 10.1049/mnl.2013.0735.

[10] A. Toncheva, R. Mincheva, M. Kancheva, N. Manolova, I. Rashkov, P. Dubois, N. 
Markova, Antibacterial PLA/PEG electrospun fibers: Comparative study between grafting and blending PEG, European Polymer Journal. 75 (2016) 223-233. doi:10.1016/j.eurpolymj.2015.12.019.

[11] K. Sungsanit, N. Kao, S.N. Bhattacharya, Properties of linear poly(lactic acid)/polyethylene glycol blends, Polymer Engineering \& Science. 52 (2012) 108-116.

[12] J.W. Tom, P.G. Debenedetti, Formation of Bioerodible Polymeric Microspheres and Microparticles by Rapid Expansion of Supercritical Solutions, Biotechnology Progress. 7 (1991) 403-411.

[13] S.G. Kazarian, Polymer processing with supercritical fluids, Polymer Science. 42 (2000) 78-101.

[14] P. Alessi, A. Cortesi, I. Kikic, F. Vecchione, Plasticization of Polymers with Supercritical Carbon Dioxide: Experimental Determination of Glass-Transition Temperatures, Journal of Applied Polymer Science. 88 (2003) 2189-2193. doi:10.1002/app.11881.

[15] A.I. Cooper, Porous Materials and Supercritical Fluids, Advanced Materials. 15 (2003) 1049-1059.

[16] L. Singh, V. Kumar, B.D. Ratner, Generation of porous microcellular 85/15 poly ((DL)lactide-co-glycolide) foams for biomedical applications, Biomaterials. 25 (2004) 26112617.

[17] D.R. Perinelli, G. Bonacucina, M. Cespi, A. Naylor, M. Whitaker, G.F. Palmieri, G. Giorgioni, L. Casettari, Evaluation of $P(L) L A-P E G-P(L) L A$ as processing aid for biodegradable particles from gas saturated solutions (PGSS) process, International Journal of Pharmaceutics. 468 (2014) 250-257.

[18] A. Naylor, A.L. Lewis, L. Ilium, Supercritical fluid-mediated methods to encapsulate drugs: recent advances and new opportunities, Therapeutic Delivery. 2 (2011) 15511565.

[19] C. Gutierrez, J.F. Rodriguez, I. Gracia, A. de Lucas, M.T. Garcia, Modification of polystyrene properties by CO2: Experimental study and correlation, Journal of Applied Polymer Science. 132 (2015). 
[20] O.R. Davies, A.L. Lewis, M.J. Whitaker, H. Tai, K.M. Shakesheff, S.M. Howdle, Applications of supercritical $\mathrm{CO}(2)$ in the fabrication of polymer systems for drug delivery and tissue engineering, Advanced Drug Delivery Reviews. 60 (2008) 373-387. doi:10.1016/j.addr.2006.12.001.

[21] D. Wu, L. Wu, M. Zhang, Y. Zhao, Viscoelasticity and thermal stability of polylactide composites with various functionalized carbon nanotubes, Polymer Degradation and Stability. 93 (2008) 1577-1584.

[22] E. Oliaei, B. Kaffashi, S. Davoodi, Investigation of structure and mechanical properties of toughened poly(L-lactide)/thermoplastic poly(ester urethane) blends, Journal of Applied Polymer Science. 133 (2016) 1-13. doi:10.1002/app.43104.

[23] M. Xie, H. Li, Viscosity reduction and disentanglement in ultrahigh molecular weight polyethylene melt: Effect of blending with polypropylene and poly(ethylene glycol), $\begin{array}{llll}\text { European } & \text { Polymer Journal. } 43 \quad \text { (2007) }\end{array}$ doi:10.1016/j.eurpolymj.2007.05.016.

[24] A. Babaei, A. Arefazar, Structural, rheological, and mechanical properties of PA6/SAN/SEBS ternary blend/organoclay nanocomposites, Journal of Applied Polymer Science. 132 (2015) n/a-n/a.

[25] S. Djellali, T. Sadoun, N. Haddaoui, A. Bergeret, Viscosity and viscoelasticity measurements of low density polyethylene/poly(lactic acid) blends, Polymer Bulletin. 72 (2015) 1177-1195. doi:10.1007/s00289-015-1331-6.

[26] H. Liao, L. Zheng, Y. Hu, X. Zha, X. Xu, Y. Wen, G. Tao, C. Liu, Dynamic rheological behavior of reactively compatibilized polypropylene/polyamide 6 blending melts, Journal of Applied Polymer Science. 132 (2015) n/a-n/a.

[27] Y. Zhao, H.-X. Huang, Y.-K. Chen, Dynamic rheology-morphology relationship of PP/EPDM blends prepared by melt mixing under Sc-CO2, Polymer Bulletin. 64 (2010) 291-302.

[28] D. Wu, Y. Zhang, M. Zhang, W. Zhou, Phase behavior and its viscoelastic response of polylactide/poly( $\varepsilon$-caprolactone) blend, European Polymer Journal. 44 (2008) 21712183. doi:10.1016/j.eurpolymj.2008.04.023. 
[29] L.J. Gerhardt, C.W. Manke, E. Gulari, Rheology of polydimethylsiloxane swollen with supercritical carbon dioxide, Journal of Polymer Science Part B: Polymer Physics. 35 (1997) 523-534. doi:10.1002/(SICI)1099-0488(199702)35:3<523::AIDPOLB11>3.0.CO;2-J.

[30] D. Gourgouillon, H.M.N.T. Avelino, J.M.N.A. Fareleira, M. Nunes da Ponte, Simultaneous viscosity and density measurement of supercritical CO2-saturated PEG 400, Journal of Supercritical Fluids. 13 (1998) 177-185. doi:10.1016/S08968446(98)00050-3.

[31] J.R. Royer, Y.J. Gay, J.M. Desimone, S.A. Khan, High-pressure rheology of polystyrene melts plasticized with CO2: Experimental measurement and predictive scaling relationships, Journal of Polymer Science Part B-Polymer Physics. 38 (2000) 3168-3180.

[32] J.R. Royer, Y.J. Gay, A. M., J.M. DeSimone, S.A. Khan, Polymer Melt Rheology With HighPressure CO2 Using A Novel Magnetically Levitated Sphere Rheometer, Polymer. 43 (2002) 2375-2383.

[33] M. Lee, C.B. Park, C. Tzoganakis, Measurements and Modeling of PS/Supercritical CO, Solution Viscosities, Polymer Engineering and Science. 39 (2004) 99-109.

[34] B. Calvignac, E. Rodier, J.J. Letourneau, P. Vitoux, C. Aymonier, J. Fages, Development of an improved falling ball viscometer for high-pressure measurements with supercritical CO2, Journal of Supercritical Fluids. 55 (2010) 96-106. doi:10.1016/j.supflu.2010.07.012.

[35] C.A. Kelly, S.M. Howdle, K.M. Shakesheff, M.J. Jenkins, G.A. Leeke, Viscosity studies of poly(DL-lactic acid) in supercritical CO2, Journal of Polymer Science Part B: Polymer Physics. 50 (2012) 1383-1393.

[36] C.A. Kelly, S.H. Murphy, G.A. Leeke, S.M. Howdle, K.M. Shakesheff, M.J. Jenkins, Rheological studies of polycaprolactone in supercritical CO2, European Polymer Journal. 49 (2013) 464-470.

[37] M.K. Hrnčič, M. Škerget, Ž. Knez, Density and viscosity of the binary polyethylene glycol/CO2 systems, The Journal of Supercritical Fluids. 95 (2014) 641-668. doi:10.1016/j.supflu.2014.09.045. 
[38] S. Curia, D.S.A. De Focatiis, S.M. Howdle, High-pressure rheological analysis of CO2induced melting point depression and viscosity reduction of poly( $\varepsilon$-caprolactone), Polymer. 69 (2015) 17-24. doi:10.1016/j.polymer.2015.05.026.

[39] M. Nobelen, S. Hoppe, C. Fonteix, F. Pla, M. Dupire, B. Jacques, Modeling of the rheological behavior of polyethylene/supercritical <mml:math altimg="si183.gif" display="inline" overflow="scroll" xmlns:xocs="http://www.elsevier.com/xml/xocs/dtd" xmlns:xs="http://www.w3.org/2001/XMLSchema" xmlns:xsi="http://www.w3.org/2, Chemical Engineering Science. 61 (2006) 5334-5345. doi:10.1016/j.ces.2006.03.052.

[40] D. Raps, T. Koppl, A.R. de Anda, V. Altstadt, Rheological and crystallisation behaviour of high melt strength polypropylene under gas-loading, Polymer. 55 (2014) 1537-1545.

[41] C. Gutiérrez, M.T. Garcia, S. Curia, S.M. Howdle, J.F. Rodriguez, The effect of CO2 on the viscosity of polystyrene/limonene solutions, Journal of Supercritical Fluids. 88 (2014) 26-37. doi:10.1016/j.supflu.2014.01.012.

[42] N.M.B. Flichy, C.J. Lawrence, S.G. Kazarian, Rheology of Poly(propylene glycol) and Suspensions of Fumed Silica in Poly(propylene glycol) under High-Pressure CO 2, Industrial \& Engineering Chemistry Research. 42 (2003) 6310-6319. doi:10.1021/ie030019l.

[43] C.A. Kelly, A. Naylor, L. Illum, K.M. Shakesheff, S.M. Howdle, Supercritical CO2: A Clean and Low Temperature Approach to Blending PDLLA and PEG, Advanced Functional Materials. 22 (2012) 1684-1691. doi:10.1002/adfm.201101889.

[44] P.J. Carreau, Rheological Equations from Molecular Network Theories, Transactions of The Society of Rheology (1957-1977). 16 (1972) 99-127.

[45] J.M. Dealy, R.G. Larson, Structure and rheology of molten polymers : from structure to flow behavior and back again, Hanser Publishers, 2006.

[46] J.R. Dorgan, J.S. Williams, D.N. Lewis, Melt rheology of poly(lactic acid): Entanglement and chain architecture effects, Journal of Rheology. 43 (1999) 1141. doi:10.1122/1.551041. 
[47] J.D. Ferry, Viscoelastic properties of polymers, J. Wiley, 1980.

[48] B.A. Miller-Chou, J.L. Koenig, A review of polymer dissolution, Progress in Polymer Science (Oxford). 28 (2003) 1223-1270. doi:10.1016/S0079-6700(03)00045-5.

[49] O. Martin, L. Avérous, Poly(lactic acid): plasticization and properties of biodegradable multiphase systems, Polymer. 42 (2001) 6209-6219. doi:10.1016/S00323861(01)00086-6.

[50] H. Tai, M.L. Mather, D. Howard, W. Wang, L.J. White, J.A. Crowe, S.P. Morgan, A. Chandra, D.J. Williams, S.M. Howdle, K.M. Shakesheff, J. Darr, P. Layrolle, T. Buckland, Control of pore size and structure of tissue engineering scaffolds produced by supercritical fluid processing - Discussion with reviewers, European Cells \& Materials. 14 (2007) 76-77. doi:vol014a07 [pii].

[51] A.R. Goddard, S. Pérez-Nieto, T.M. Passos, B. Quilty, K. Carmichael, D.J. Irvine, S.M. Howdle, Controlled polymerisation and purification of branched poly(lactic acid) surfactants in supercritical carbon dioxide, Green Chem. 18 (2016) 4772-4786. doi:10.1039/C6GC00745G.

[52] Molecular Weight of PLA with the BI-MwA, Http://www.brookhaveninstruments.com/literature/library/molecular-Weight-of-Plawith-the-Bi-Mwa. http://www.brookhaveninstruments.com/literature/library/molecular-weight-of-plawith-the-bi-mwa (accessed June 16, 2016).

[53] Sample Name : Poly ( ethylene glycol ) dibenzylmethylene Terminated Sample \#: P56 P 5607 Structure : Composition : Synthesis Procedure : Poly (ethylene glycol) is obtained by living anionic polymerization and the reaction. Scheme of the polymerization, http://www.polymersource.com/dataSheet/P5607-EO\%20(PEO).pdf. (n.d.). http://www.polymersource.com/dataSheet/P5607-EO (PEO).pdf (accessed June 16, 2016).

[54] A. Dag, H. Durmaz, V. Kirmizi, G. Hizal, U. Tunca, An easy way to the preparation of multi-miktoarm star block copolymers via sequential double click reactions, Polymer Chemistry. 1 (2010) 621-623. doi:10.1039/c0py00059k. 
